\title{
Article \\ Experimental Investigation of Vibration Analysis on Implant Stability for a Novel Implant Design
}

\author{
Shouxun Lu ${ }^{1, *(\mathbb{D}}$, Benjamin Steven Vien ${ }^{1}\left(\mathbb{D}\right.$, Matthias Russ ${ }^{2,3}$, Mark Fitzgerald ${ }^{2,3}$ and Wing Kong Chiu ${ }^{1}(\mathbb{D}$ \\ 1 Department of Mechanical \& Aerospace Engineering, Monash University, Melbourne, VIC 3800, Australia; \\ ben.vien@monash.edu (B.S.V.); wing.kong.chiu@monash.edu (W.K.C.) \\ 2 The Alfred Hospital, Melbourne, VIC 3004, Australia; m.russ@alfred.org.au (M.R.); \\ m.fitzgerald@alfred.org.au (M.F.) \\ 3 National Trauma Research Institute, Melbourne, VIC 3004, Australia \\ * Correspondence: shouxun.lu@monash.edu
}

check for updates

Citation: Lu, S.; Vien, B.S.; Russ, M.; Fitzgerald, M.; Chiu, W.K.

Experimental Investigation of

Vibration Analysis on Implant

Stability for a Novel Implant Design.

Sensors 2022, 22, 1685. https://

doi.org/10.3390/s22041685

Academic Editor: Keat Ghee Ong

Received: 11 January 2022

Accepted: 17 February 2022

Published: 21 February 2022

Publisher's Note: MDPI stays neutral with regard to jurisdictional claims in published maps and institutional affiliations.

Copyright: (C) 2022 by the authors. Licensee MDPI, Basel, Switzerland. This article is an open access article distributed under the terms and conditions of the Creative Commons Attribution (CC BY) license (https:// creativecommons.org/licenses/by/ $4.0 /)$.

\begin{abstract}
Osseointegrated prostheses are widely used following transfemoral amputation. However, this technique requires sufficient implant stability before and during the rehabilitation period to mitigate the risk of implant breakage and loosening. Hence, reliable assessment methods for the osseointegration process are essential to ensure initial and long-term implant stability. This paper researches the feasibility of a vibration analysis technique for the osseointegration (OI) process by investigating the change in the dynamic response of the residual femur with a novel implant design during a simulated OI process. The paper also proposes a concept of an energy index (the E-index), which is formulated based on the normalized magnitude. To illustrate the potential of the E-index, this paper reports on changes in the vibrational behaviors of a $133 \mathrm{~mm}$ long amputated artificial femur model and implant system, with epoxy adhesives applied at the interface to simulate the OI process. The results show a significant variation in the magnitude of the colormap against curing time. The study also shows that the E-index was sensitive to the interface stiffness change, especially during the early curing process. These findings highlight the feasibility of using the vibration analysis technique and the E-index to quantitatively monitor the osseointegration process for future improvement on the efficiency of human health monitoring and patient rehabilitation.
\end{abstract}

Keywords: osseointegration implant; structural health monitoring; vibrational analysis

\section{Introduction}

The traditional treatment for transfemoral amputation is the prosthetic socket system, which consists of an artificial socket providing a secure connection between the residual limb and the prostheses for the transfemoral amputee [1,2]. While enormous advances in the material and design have been utilized to improve the comfort and performance of the socket system, there are several major drawbacks, which include skin irritation and pressure sores as compression occurs between the residual limb and socket transfers via the soft tissue, which compromises the quality of life of the amputee [1,3-5]. Furthermore, for extremely short or severely wounded residual femurs, socket devices may not be an appropriate treatment to provide adequate stability and prompt osseointegration (OI) $[1,6,7]$.

The state-of-the-art method that has been widely investigated and employed is the use of osseointegrated prostheses, consisting of a metal implant that is inserted into the skeletal system, providing a direct connection between the artificial limb and the residual leg [8,9] without the interference of the soft tissue $[6,8,10]$. A common material for the implant is titanium alloy due to its excellent biocompatibility and high resistance to corrosion and repeated stress loading [11,12]. Amputees treated with a transfemoral osseointegrated implant (TFOI) require a two-stage surgical procedure to accomplish a successful implantation. During the first stage, the metal implant is inserted into the 
medullary cavity and left unload for typically six months [2,13]. Afterwards, the loading on the implant will gradually increase until the TFOI is capable of the full weight load bearing. This process is known as the rehabilitation period, which may take up to 18 months [14]. The direct mechanical connection formed during the OI process provides better joint mobility and improves the control of the prostheses compared to the socket system $[9,10,14]$. Osseointegrated prostheses also offer further advantages, including better bone conditions, reducing the risk of skin infection, and sensory feedback from the ground during the movement $[3,6,15,16]$.

Even though the OI system has significantly eliminated some limitations of the socket system, there are various challenges that remain for osseointegrated implants; in particular, a long rehabilitation is required to conservatively ensure the implant is securely bonded with residual femur $[4,13,17]$. The OI system requires sufficient implant stability before and during the rehabilitation period to prevent any potential implant breakage and loosening $[1,4,14,15]$. In addition, the works in $[18,19]$ reported that periprosthetic infections next to the exposed metal surface could lead to implant loosening.

Hence, reliable assessment methods for the OI process are essential to ensure initial and long-term implant stability. Moreover, early recognition of the implant loosening could also aid in the detection of the infection to prevent severe consequences such as amputations and sometimes death. Currently, various examination methods such as clinical X-ray and magnetic resonance imaging are used to assess the in vivo implant stability $[2,20,21]$. Nonetheless, these conventional methods are known to be subjective and qualitative since their accuracies are mainly based on the interpretation and judgment of the surgeon rather than using quantitative justifications (i.e., the stiffness of the connection) [1,21-24]. Furthermore, current amputees are also at potential risk of being exposed to radiation [1,25]. Moreover, the applications of these techniques are limited by the measurement accuracy due to the diffraction effect of the metal intramedullary part $[21,22,25]$. Therefore, there is an increasing need to quantitatively monitor the degree of OI and prevent implant loosening in long-term applications.

Recently, there is significant interest in the structural health monitoring techniques, which are widely used in monitoring the integrity of structures in the OI system, aiming to increase the reliability and accuracy of assessment of the OI and implant stability. Vibration analysis methods have been actively investigated and used as a non-invasive technique to assess osseointegration-related structures, such as dental implants $[17,20,22,26]$ and total hip arthroplasty implants [2,25,27-31]. Furthermore, the research on vibration analysis methods has extended to the field of transfemoral implants, and the dynamic responses of the OI system are utilized to assess the OI process and implant stability using resonance frequency analysis (RFA) and modal analysis [2,20,21,32-34].

In the research on dental implant stability conducted by Huang et al. [35], an implant was installed into predrilled cavities of 3.75 and $5 \mathrm{~mm}$ in six rabbits to simulate secure-fit and loose-fit conditions, respectively. The result demonstrated that the femur with the loose-fit implant had a lower initial resonance frequency, compared to the one with a secure-fit condition. In addition, during the OI stage, the resonance frequency significantly increased and peaked under both conditions when the implant was fully bonded with the femur. Similarly, the research on the OPRA implant presented by [2] conducted nine tests during the rehabilitation process of a 40-year-old male patient. The result demonstrated a reduction in resonance frequency after the first weight bearing, which indicated a lack of osseointegration. Then, the resonance frequency gradually increased until the patient was capable of a full bodyweight load.

However, several authors suggested that the RFA should be used in combination with other assessment methods to determine the dental implant stability [36-38]. The research on dental implants reported by $[39,40]$ demonstrated a poor correlation between RF and boneimplant contact. These findings may hinder the future application of RFA in monitoring the stability of transfemoral OI implants. Moreover, the research conducted by [20,21] showed that the modal analysis is possible to assess the degree of OI, except with using particular 
modes over a specific frequency range. Hence, there is still a significant need for universal and robust monitoring techniques for the transfemoral osseointegrated implant.

This paper investigates the feasibility of a vibration analysis technique on the OI process by investigating the change in the dynamic response of the residual femur with a novel implant design during a simulated OI process. The novel osseointegrated implant was developed based on the design concept proposed by Russ, Fitzgerald, and Chiu (US20200188140) [41]. This study also proposes the concept of using normalized energy difference to formulate an energy index (E-index), which could quantify the stages of OI. Moreover, this paper also investigates the effect of implant stiffness on the accuracy of the E-index using different intramedullary stem designs.

\section{Materials and Methods}

\subsection{Specimens}

An amputated $133 \mathrm{~mm}$ long Sawbone ${ }^{\circledR}$ composite femur specimen, which represents the most common osteotomy level of $250 \mathrm{~mm}$ above the knee, was adopted in this experiment. The femur model was prepared with three specifically designed 3D-printed plastic osseointegrated implants. The first implant model, shown in Figure 1a, consists of three components: an extramedullary (EM) strut, an intramedullary (IM) stem, and a stem. The EM strut aimed to provide initial stability when first inserted into the remnant stem. During the rehabilitation period, the bone tissue slowly grew on the surface of the IM stem, forming a secure connection between the femur and implant. The extended base, which was modified from the prostheses stem, provided a striking point for the experiment. The second implant model, shown in Figure 1b, is the same as the first model but with a hollow IM stem of $0.5 \mathrm{~mm}$ in thickness. In addition, amputation normally occurs at different locations. The anatomic cross-section of the remnant stem is not exactly same (refer to Figure 2). Therefore, two oval-shaped implant models, which have the same IM stem and extended strut dimension as the triangular implants, were investigated (see Figure 3).

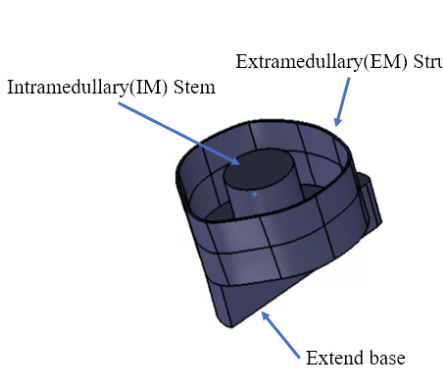

(a)

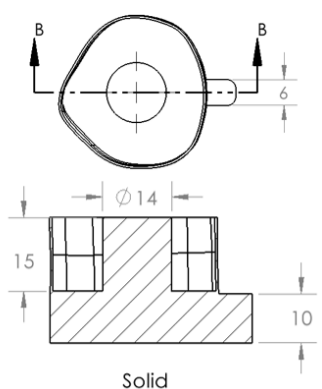

Solid

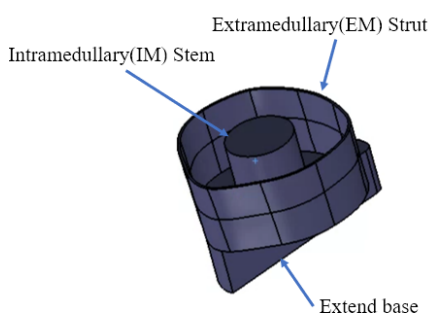

(b)
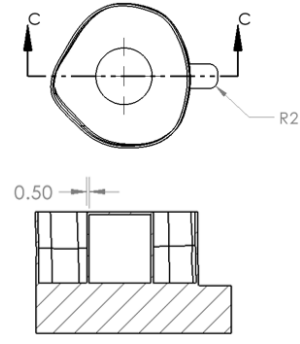

Hollow

Figure 1. Triangular-shaped implant model and dimension developed based on Patent US20200188140: (a) implant with solid IM stem and (b) implant with hollow IM stem.

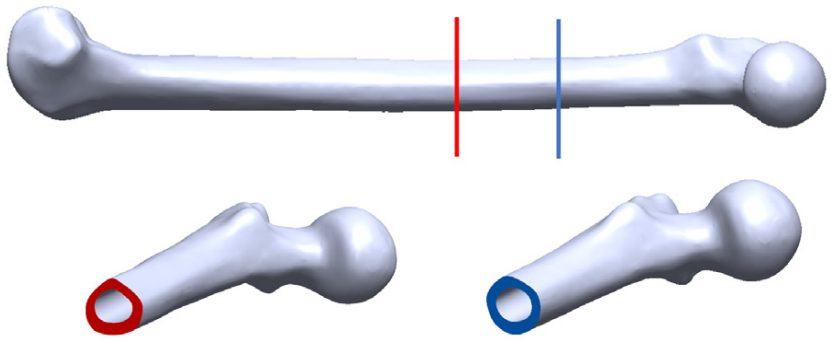

Figure 2. 3D femur model demonstrating the triangular and oval cross-section for different anatomic locations. 


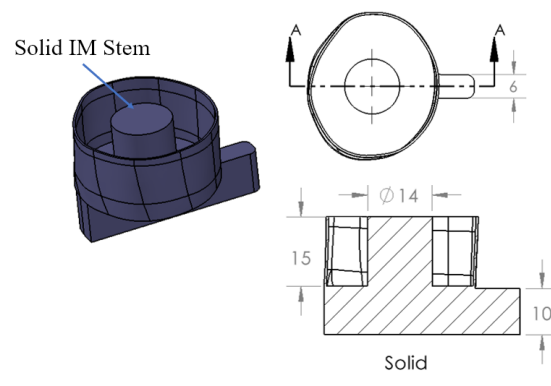

(a)
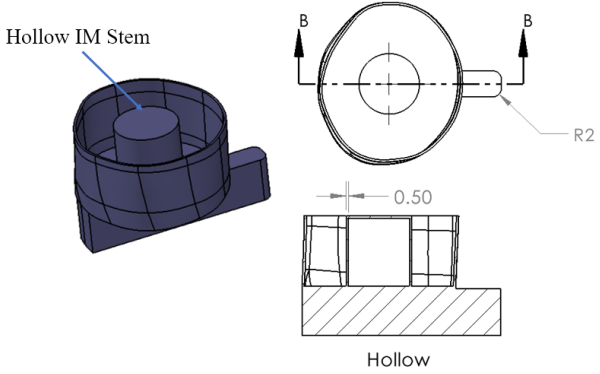

(b)

Figure 3. Oval-shaped implant model and dimension developed based on Patent US20200188140: (a) implant with solid IM stem and (b) implant with hollow IM stem.

An epoxy adhesive with a setting time (gel time) of $5 \mathrm{~min}$ and a fully cured time of $16 \mathrm{~h}$ was used to simulate the process of OI [23,24,42-45]. The application of epoxy adhesive is not an accurate representation of the OI process; however, the change in the material properties as a result of the curing process mimics the behavior during OI [24]. Due to the OI mainly occurring at the surface of the IM stem, the epoxy was applied to the interface between the femur model and the IM stem. The diameter of the IM stem was slightly reduced by $2 \mathrm{~mm}$, (see Figure 4), allowing the adhesive to have a similar thickness of bone tissue coverage required for the in vivo implant [1]. Triangular and oval implant conditions were carried out four and three times, respectively, to investigate the effect on the E-index due to the variance in the curing time, adhesive quality, and cross-section shape. The results of the tests were notated as 'Shape-Solid-number' or 'Shape-Hollow-number'; for example, Tri-Solid-3 represented test 3 under a triangular solid condition.

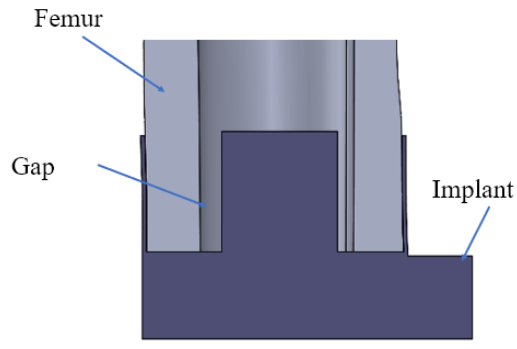

Figure 4. Cross-section of femur-implant interface.

\subsection{Experimental Setup}

The proximal end of the residual femur was clamped by a 3D-printed vice, which had jaws fitted with the shape of the femur head, providing relatively rigid fixation. An instrumented impact hammer (B\&K Type 8206 Hottinger Bruel \& Kjaer UK Ltd., Royston, Hertfordshire, UK) was used to provide a torsional moment input for the femur-implant system. The input force was intentionally not recorded, allowing the force variation during the experiment to aid the assessment of the reliability of the measurement technique proposed [46]. Two unidirectional accelerometers (B\&K Type 4507 Hottinger Bruel \& Kjaer UK Ltd., Royston, Hertfordshire, UK) were attached to the locations S1 and S2, measured in the y-direction as described in Figure 5. The measuring range of the accelerometers was set up before the measuring process started according to the expected values of the vibration. The voltages from the accelerometers were recorded and analyzed by B\&K RT Pro Photon (Hottinger Bruel \& Kjaer UK Ltd., Royston, Hertfordshire, UK) with a frequency bandwidth of $14.4 \mathrm{kHz}$ and a frequency resolution of $1.125 \mathrm{~Hz}$. The sampling rate of the B\&K RT Pro Photon was $32,768 \mathrm{~Hz}$. The spectra were averaged over 10 samples to achieve a good signal-to-noise ratio. The time of the first recorded experimental data is the reference time $(0 \mathrm{~s})$. A total of $1140 \mathrm{~s}$ of cure time were recorded. The cross-spectrum of the two sensors was obtained at $30 \mathrm{~s}$ intervals for the first $300 \mathrm{~s}$ and $60 \mathrm{~s}$ intervals for the remaining $840 \mathrm{~s}$. 


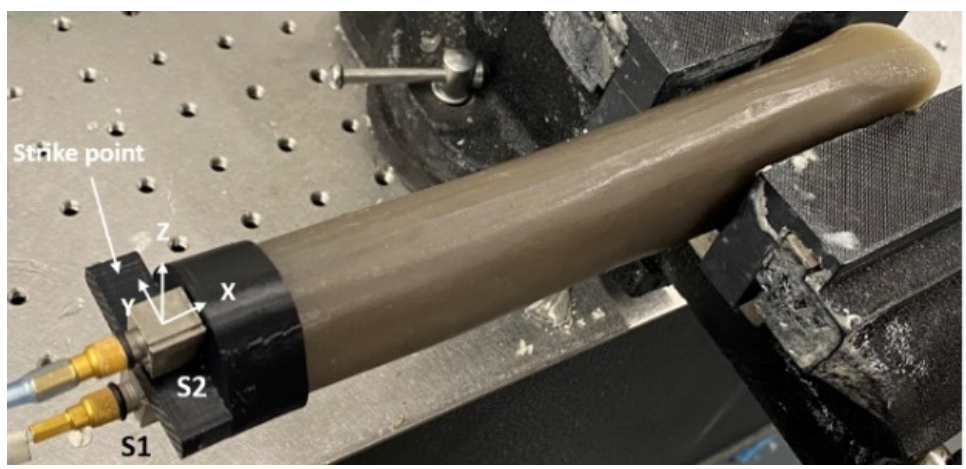

Figure 5. Image of experimental setup with the orientation of sensors.

The application of the two-sensor setup was developed in our earlier work $[42,46,47]$ to identify the bending/torsional modes and to determine the integrity of the signal via a coherence function. However, in the work presented, the ability to separate these vibrational modes is not crucial in determining the E-index.

To aid with the visual identification of the dynamic response during the cure time, MATLAB 2020a (MathWorks, Natick, MA, USA) was used to generate the cross-spectrum and colormap with a normalized magnitude on a logarithmic scale. The cross-spectrum and colormap demonstrated the magnitude change along with the frequency at certain time points and continuous time from 0 to $1140 \mathrm{~s}$, respectively. Furthermore, a quantitative parameter: the energy index (E-index) based on the previous research by Ong et al. [48,49], Vien et al. [24,50], and Wing et al. [23,47], was also adopted in this study to reveal the association between vibrational response and stage of OI. The E-index was defined as the area under the magnitude plot within a certain frequency bandwidth, from $f_{0}$ to $f_{i}$, relative to the total area $\left(f_{0}\right.$ to $\left.f_{1}\right)$, as below:

$$
\begin{gathered}
E(t)=E_{f i}(t) / E_{\text {total }}(t) \\
E_{f_{i}}(t)=\int_{f_{0}}^{f_{i}} M^{2}(f, t) d f \\
E_{\text {total }}(t)=\int_{f_{0}}^{f_{1}} M^{2}(f, t) d f
\end{gathered}
$$

where $M(f, t)$ is the normalized magnitude at frequency $f$ and cure time $t, E_{\text {total }}(t)$ is the area covered by the cross-spectrum plot from $f_{0}$ to $f_{1}$ at cure time $t$, and $E_{f_{i}}$ is the area covered by the cross-spectrum plot from $f_{0}$ to $f_{i}$ at cure time $t$.

Additionally, the coherence function, which was used to determine the frequency bound of the E-index, is calculated for the two sensors as defined below:

$$
\text { Coherece }=\frac{\left|\overline{G_{11}(f)} G_{22}(f)\right|^{2}}{G_{11}(f) G_{22}(f)}
$$

where $G_{11}(f)$ and $G_{22}(f)$ are the autospectra of sensors 1 and 2, respectively, and $\overline{G_{11}(f)}$ is the complex conjugate of $G_{11}(f)$.

The determination of the upper $\left(f_{1}\right)$ and lower $\left(f_{0}\right)$ bound frequency will be discussed in the next section.

\section{Results}

\subsection{Determination of Upper Frequency Bound}

The coherence of the two accelerometers in the frequency ranged from 0 to $14.4 \mathrm{kHz}$ for Tri-Solid conditions against the cure time, as shown in Figure 6. The result showed that the coherence under $10 \mathrm{kHz}$ was general above 0.8 , indicating a good signal-to-noise ratio. 
A similar phenomenon also occurred in the result of the Tri-Hollow and Oval conditions. Therefore, the upper $\left(f_{1}\right)$ bound frequency was set to $10 \mathrm{kHz}$ to reduce the error caused by the noise.
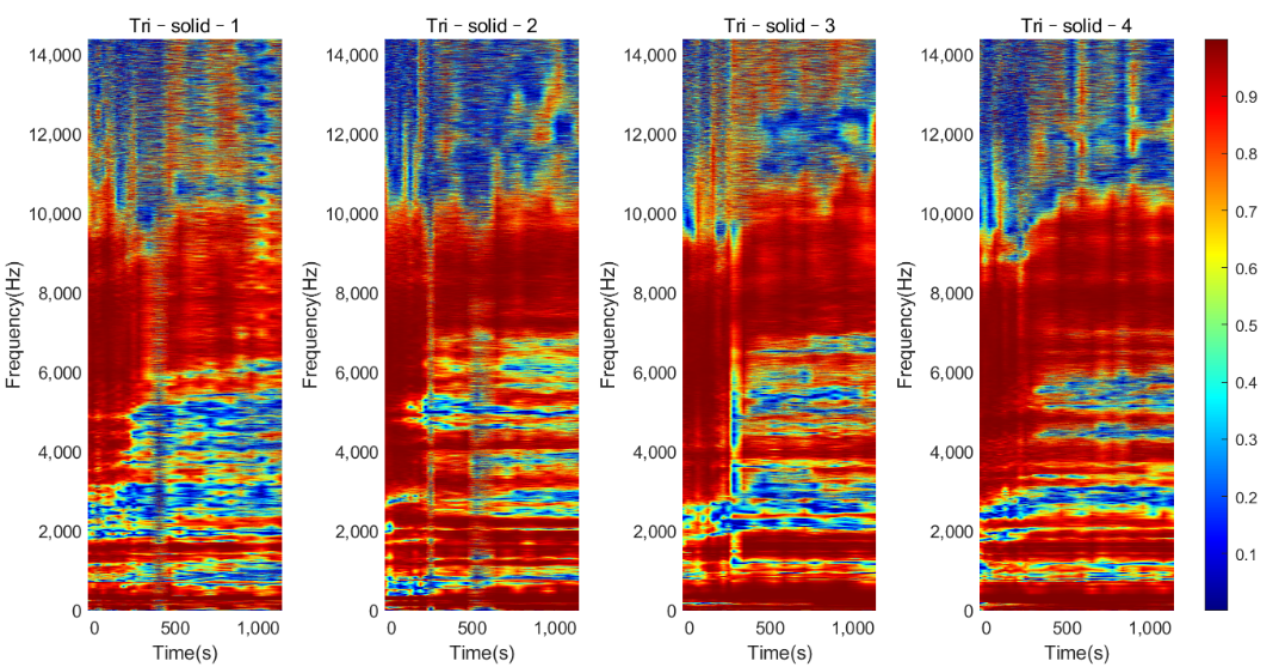

Figure 6. Plots of the coherence development against the cure time for triangular implants with a solid IM stem.

\subsection{Triangular-Shaped Implant}

\subsubsection{Colormap of Magnitude}

Figure 7 shows the normalized magnitude development as the function of cure time for the frequency range of 0 to $10 \mathrm{kHz}$ for Tri-Solid-2. During the early curing of the epoxy, the implant was not fully integrated with the femur; the dampening effect of the soft epoxy suppressed the high-frequency modes leading to a flat cross-spectrum, except for several strong vibrational modes located below $1000 \mathrm{~Hz}$. The comparison of the cross-spectrum over the cure time suggested that several peaks in the high-frequency range appeared as the curing of the epoxy, such as the frequencies $3279 \mathrm{~Hz}$ and $4124 \mathrm{~Hz}$, indicated in Figure 7a,b. As the cure time increased, the magnitudes of $3279 \mathrm{~Hz}$ and $4124 \mathrm{~Hz}$ significantly decreased by $4.064 \mathrm{~dB}$ and $5.940 \mathrm{~dB}$, respectively, relative to their baseline (at $0 \mathrm{~s}$ ) magnitude (Table 1). Similar phenomena were also discovered, as shown in Figures 8 and 9, for the implant with a solid and hollow IM stem, respectively. From $0 \mathrm{~s}$ to $300 \mathrm{~s}$, the resonance peaks were hard to distinguish. After the first $300 \mathrm{~s}$, the resonance peaks in the frequency band from approximately 2000 to $8000 \mathrm{~Hz}$ became noticeable for both solid and hollow implants, especially for the resonance peak within 3000 to $4000 \mathrm{~Hz}$, marked by the dotted line. This was consistent with the five-minute setting time of the epoxy used in this experiment, meaning that the sensitivity of early curing is significant after the initial bonding provided by the adhesive at the interface. The plots also demonstrate that the magnitude of the several modes below $1000 \mathrm{~Hz}$ was not affected by the interface stiffness change due to the simulated OI process. Therefore, the lower frequency $\left(f_{0}\right)$ for the E-index formula was set to $1000 \mathrm{~Hz}$ to increase the sensitivity of E-index on the OI-related stiffness change.

Table 1. Normalized magnitude in log scale for frequencies of 3279 and $4124 \mathrm{~Hz}$.

\begin{tabular}{ccccccc}
\hline $\begin{array}{c}\text { Frequency } \\
\mathbf{( H z )}\end{array}$ & $\mathbf{0 ~ s}$ & $\mathbf{1 5 0} \mathbf{s}$ & $\mathbf{3 0 0 ~ s}$ & $\mathbf{6 0 0 ~ s}$ & $\mathbf{1 1 4 0 ~ s}$ & $\begin{array}{c}\text { Change in dB } \\
\text { (Relative to 0 s) }\end{array}$ \\
\hline 3279 & -6.010 & -7.425 & -7.965 & -9.623 & -10.074 & -4.064 \\
4124 & -5.195 & -6.684 & -7.610 & -9.391 & -11.135 & -5.940 \\
\hline
\end{tabular}




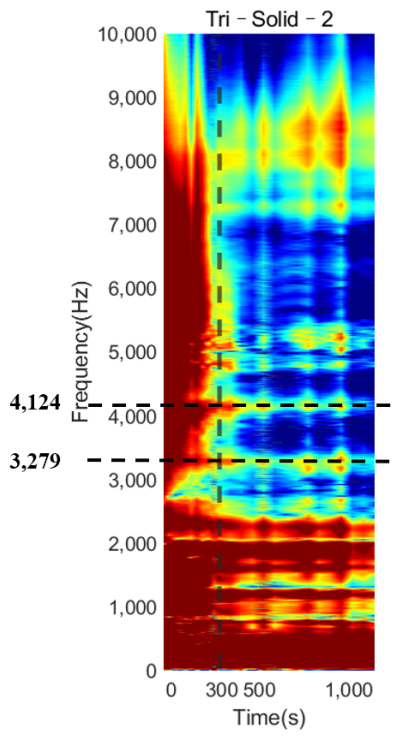

(a)

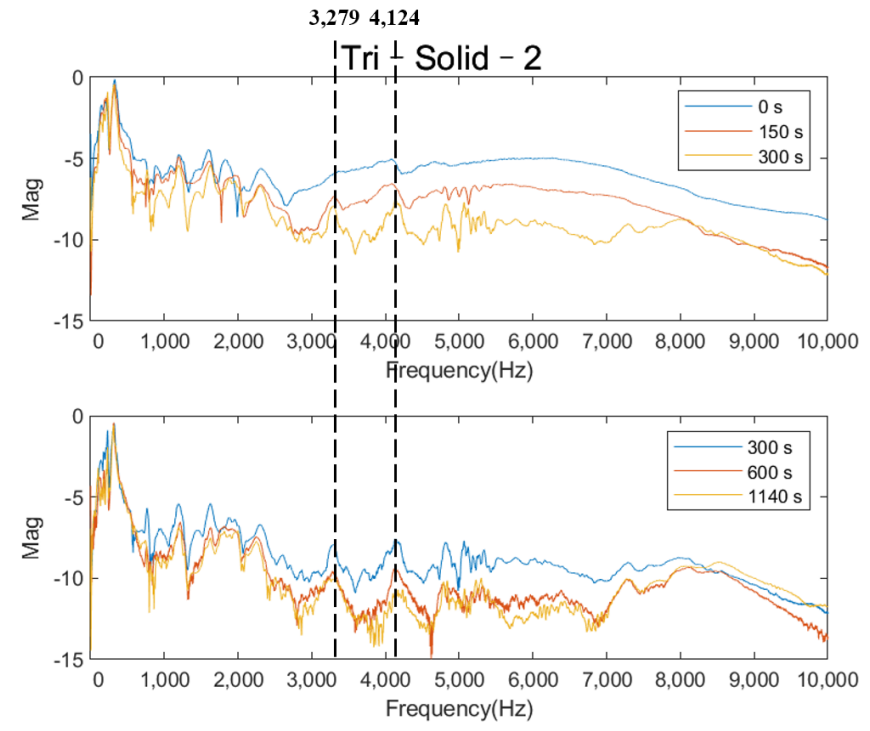

(b)

Figure 7. Plots of (a) colormap based on normalized magnitude development as the function of cure time, (b) cross-spectrum at five different cure times.
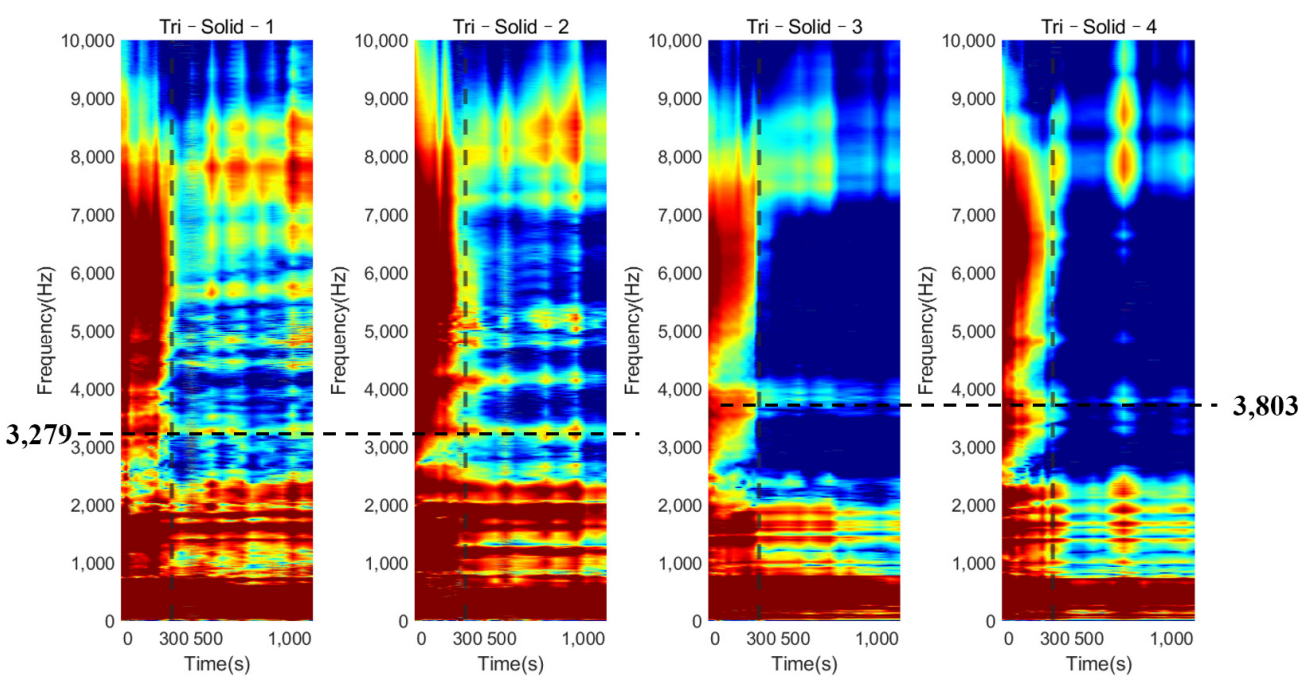

Figure 8. Plots of the normalized magnitude development as the function of cure time for triangular implants with a solid IM stem.

\subsubsection{E-Index against Frequency}

Figure 10 demonstrates the variation in the E-index at five different times $(0,150$, 300,600 , and 1140 s) of Tri-Solid-2 for the frequency ranges of $0-14.4 \mathrm{kHz}, 0-2 \mathrm{kHz}$, and $1-10 \mathrm{kHz}$, respectively. The E-index in the frequency range $1-10 \mathrm{kHz}$ showed a significant change along the cure time; nevertheless, no change in E-index for the other two frequency ranges was demonstrated in the plot. This result indicated that the energy of the vibrational modes within the frequency range $1-10 \mathrm{kHz}$ was sensitive to the stiffness change in the femur-implant interface caused by the simulated OI process.

The plots of the E-index as the function of frequency at five different times $(0,150$, 300, 600, and 1140 s) are shown in Figures 11 and 12 for the solid IM stem and hollow IM stem conditions, respectively. For both conditions, the E-index for a frequency range of $2000 \mathrm{~Hz}$ to $6000 \mathrm{~Hz}$ gradually increased over time and became stable around 1, except for the Tri-Hollow-3 condition, which was stable at 0.41 . After $300 \mathrm{~s}$, the gradient of the E-index approached zero as the femur fully bonded with the implant. The difference 
between $0 \mathrm{~s}$ and $1140 \mathrm{~s}$ gradually decreased as the frequency increased from $2000 \mathrm{~Hz}$ to $6000 \mathrm{~Hz}$. Moreover, based on Figures 8 and 9, which demonstrate significant changes in the magnitude at approximately $3500 \mathrm{~Hz}$, this means that the vibrational modes at this frequency would be more sensitive to the femur-implant interface stiffness change as compared to other frequencies. There was a significant change (at least 57\%) in the E-index at the end of the experiments, related to the baseline at $3500 \mathrm{~Hz}$ for both solid and hollow conditions, which are recorded in Table 2. Moreover, the averaged difference of the hollow condition was larger when compared to that of the solid condition. Except for this, there was no significant pattern in the E-index difference and frequencies between the solid and hollow conditions. These two conditions shared a similar trend of the E-index over the cure time.
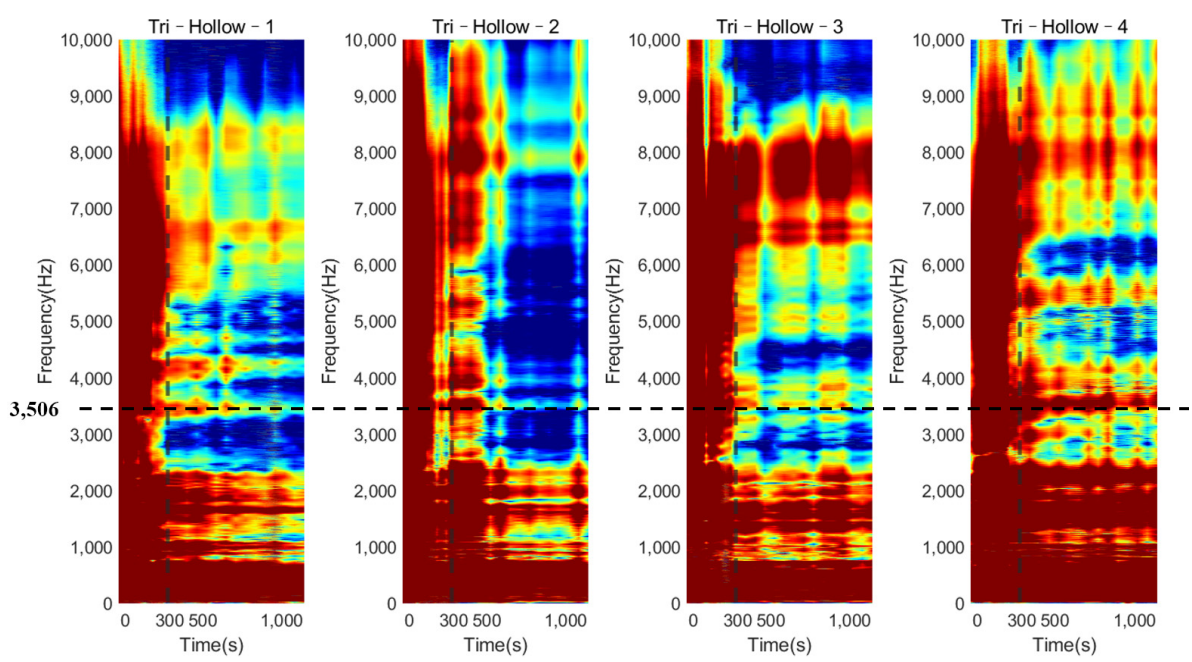

Figure 9. Plots of the normalized magnitude development as the function of cure time for triangular implants with a hollow IM stem.
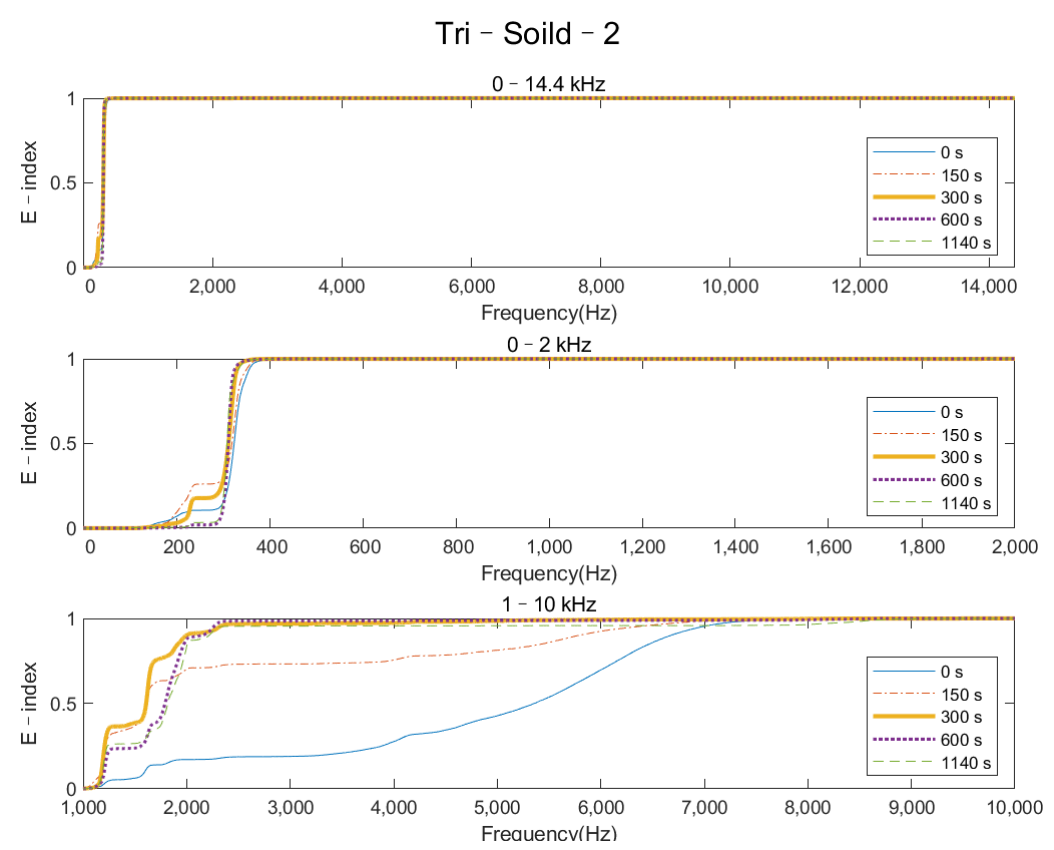

Figure 10. Plots of the E-index of triangular implants with a solid IM stem at five different times $(0,150,300,600$, and $1140 \mathrm{~s})$ for frequency ranges of $0-14.4 \mathrm{kHz}, 0-2 \mathrm{kHz}$, and $1-10 \mathrm{kHz}$. 

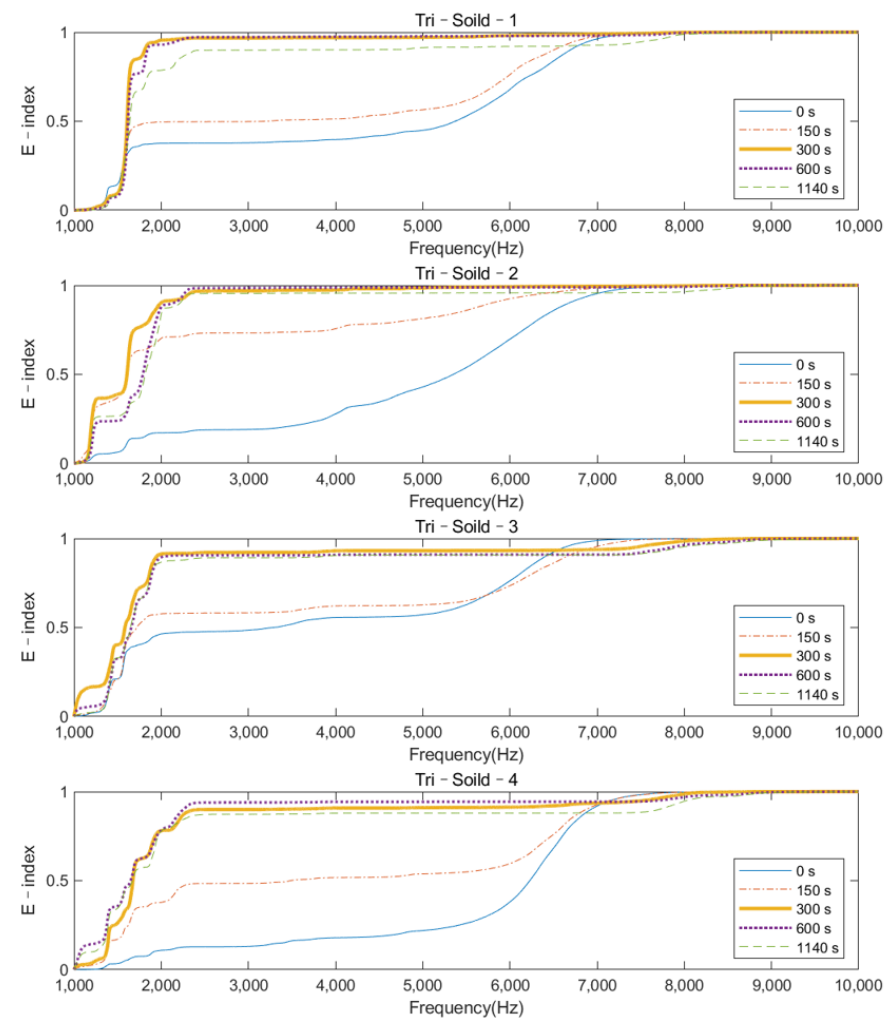

Figure 11. E-index as the function of frequency at five different times $(0,150,300,600$, and $1140 \mathrm{~s})$ for a solid IM stem condition.
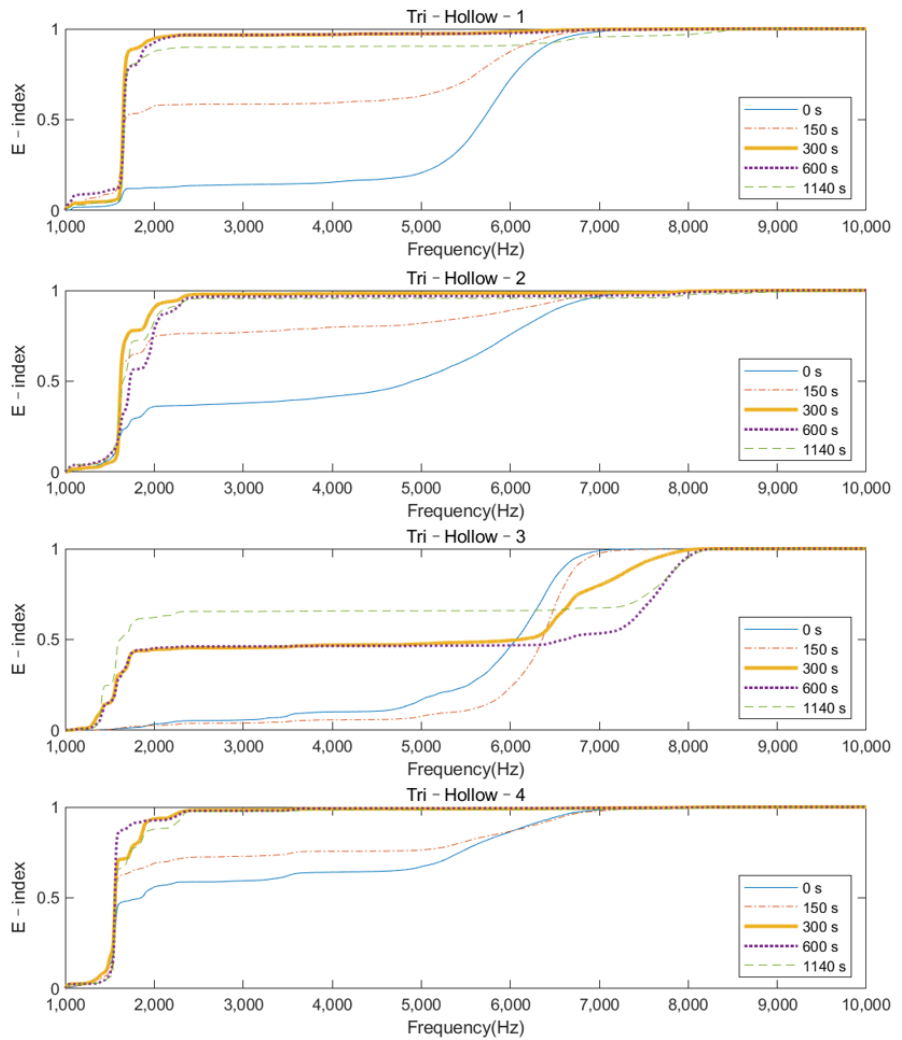

Figure 12. E-index as the function of frequency at five different times $(0,150,300,600$, and $1140 \mathrm{~s})$ for a hollow IM stem condition. 
Table 2. Difference (relative to $0 \mathrm{~s}$ for each condition) at $3500 \mathrm{~Hz}$.

\begin{tabular}{ccc}
\hline Test & \multicolumn{3}{c}{ Difference (\%) } \\
\hline & Solid & Hollow \\
\hline 1 & 132.82 & 516.53 \\
3 & 354.55 & 142.80 \\
4 & 71.81 & 713.73 \\
Averaged & 439.45 & 57.17 \\
& 249.66 & 355.04 \\
\hline
\end{tabular}

\subsubsection{E-Index against Cure Time}

The following graphs in Figure 13a,b for the solid and hollow conditions, respectively, were generated based on the E-index formula at $3500 \mathrm{~Hz}$. Figure 13a evidences that for the solid condition, the E-index increased dramatically for the first $300 \mathrm{~s}$, then the gradient of the plots approached zero, and the value stabilized above 0.8 as the implant was initially bonded with the femur. The distinct gradient change around $300 \mathrm{~s}$ coincided with the setting time of the epoxy adhesive. The E-index for the hollow condition shared similar behavior to that of the solid conditions. However, for Tri-Hollow-3 in Figure 13b, the E-index showed some fluctuations during and after the adhesive setting time. This result is noticeably different from the other data presented in this paper, which will be discussed in the discussion section. Except for this, the plots of the E-index under the solid and hollow conditions showed a clear trend that could be used to identify the stage of the OI process. The E-index offered a quantitative approach to monitor the OI process rather than one based on visual inspection of the colormap or selecting and identifying the specific frequency peaks/modes on the cross-spectrum.

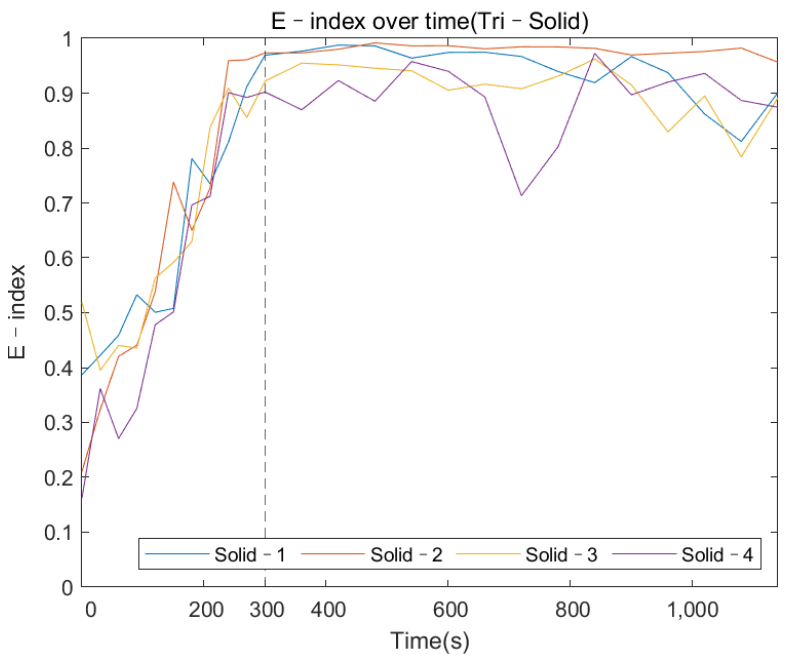

(a)

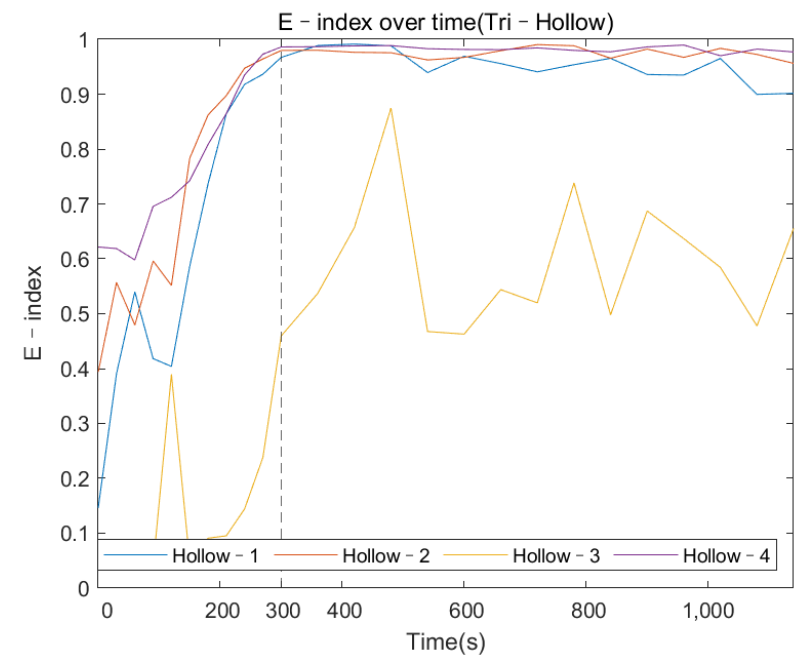

(b)

Figure 13. Variation of E-index at selected frequencies as the cure time increased for the triangular implants under (a) solid and (b) hollow conditions.

\subsection{Oval-Shaped Implant \\ 3.3.1. Colormap of Magnitude}

The colormap (refer to Figure 14) for the oval-shaped implant presented a similar trend to that of the result of the triangular implant. A significant magnitude change was identified at $300 \mathrm{~s}$ for both the solid and hollow conditions. In addition, the change in the magnitude against cure time for the modes located below $1000 \mathrm{~Hz}$ was hard to distinguish. These results coincide with those for the triangular implant, proving that the colormap of the magnitude was not affected by the cross-section of the residual femur. This result 
evidences the potential of the colormap in detecting the initial bonding of the OI process for different geometry at a fixed length of the residual femur of $133 \mathrm{~mm}$.
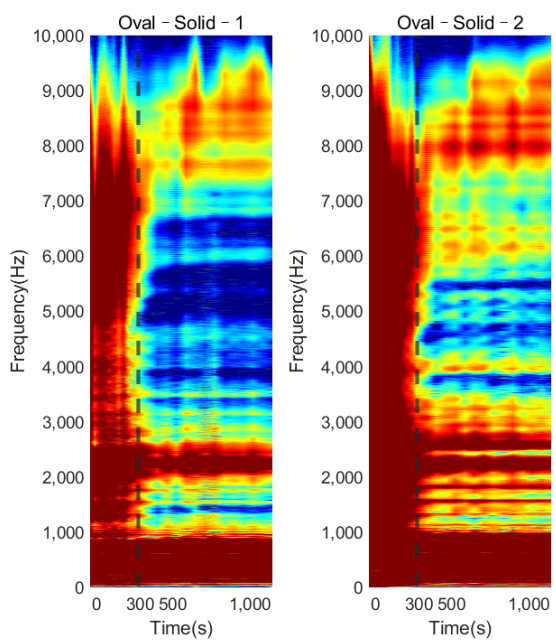

(a)
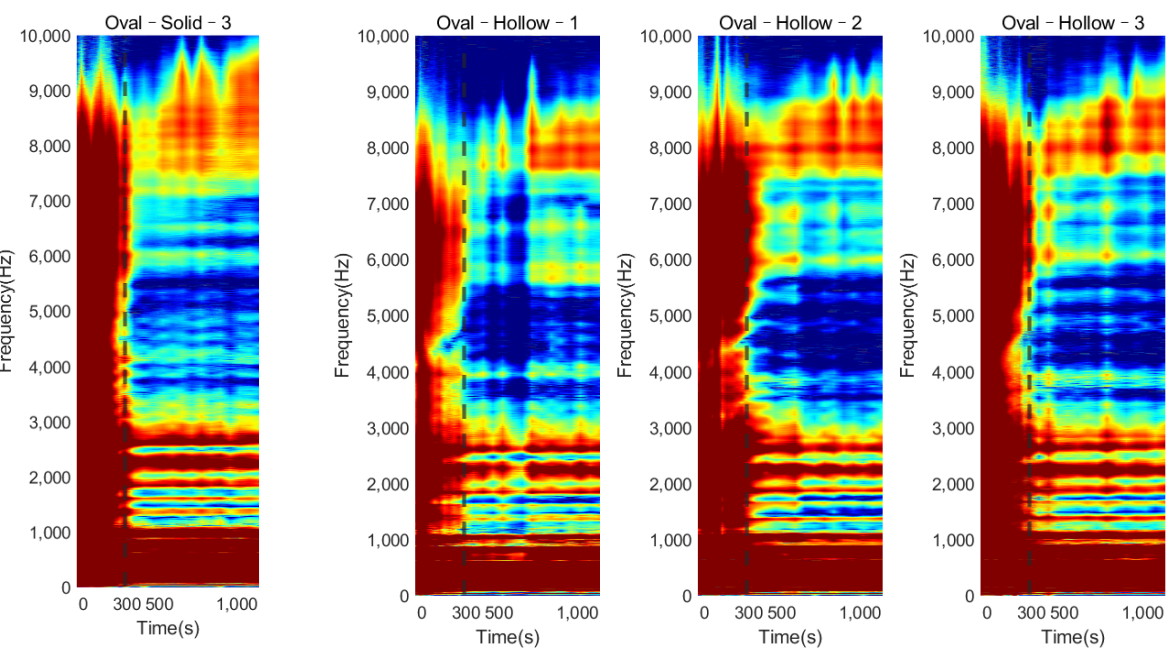

(b)

Figure 14. Plots of the normalized magnitude development as the function of cure time for oval implants with (a) solid IM stem and (b) hollow IM stem.

\subsubsection{E-Index against Cure Time}

Similar to the triangular implant, Figure 15 presents the E-index comparison between each specimen over the cure time. It is shown that the E-index steadily increased along the cure time, being stable around 0.9 at $300 \mathrm{~s}$ as the implant bonded with the femur. The curing of the adhesive resulted in a relatively high gradient for the first $300 \mathrm{~s}$. There was an increase (at least 28\%) in the E-index over the curing time for both the solid and hollow conditions, which are recorded in Table 3. However, the gradient of the E-index of the solid condition was smaller compared to that of hollow condition. In addition, the difference in the E-index relative to $0 \mathrm{~s}$ indicated that the hollow condition had a larger change in the E-index compared to that of the solid condition, which was coincident with the result of the triangular condition. This can be attributed to the fact that the similar stiffness change caused by the adhesive curing was relatively smaller in the solid implant system due to the additional stiffness of the solid IM stem. These reductions in the stiffness change between solid and hollow implant system implied that the E-index was sensitive to the stiffness of the femur-implant system, evidencing that the E-index could be a quantitative parameter to determine the degree of $\mathrm{OI}$.

Table 3. Difference (relative to $0 \mathrm{~s}$ for each condition) for oval-shaped implants.

\begin{tabular}{ccc}
\hline Test & \multicolumn{3}{c}{ Difference (\%) } \\
\hline 1 & Solid & Hollow \\
\hline 2 & 32.05 & 81.53 \\
3 & 44.93 & 36.46 \\
Averaged & 28.11 & 152.37 \\
& 35.03 & 90.12 \\
\hline
\end{tabular}




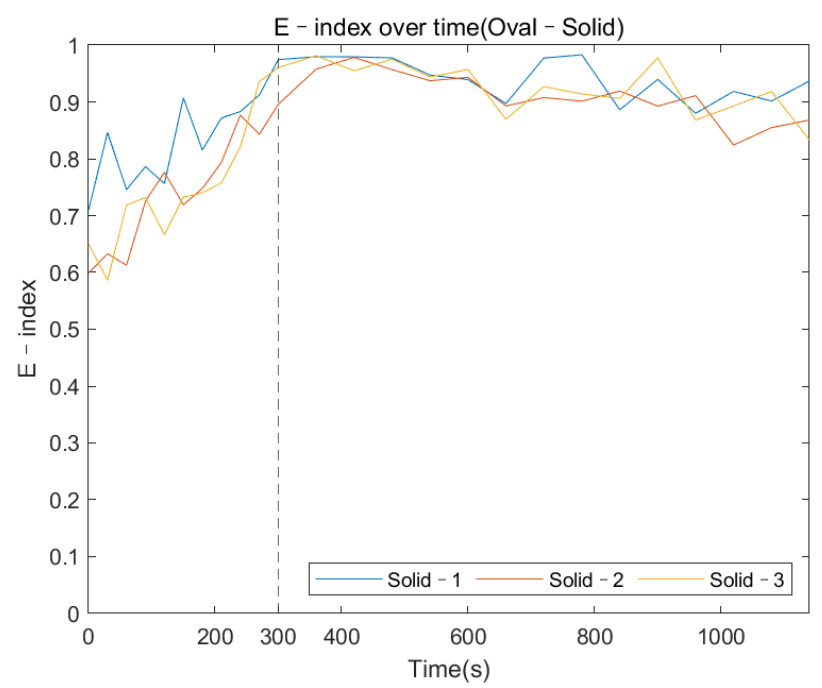

(a)

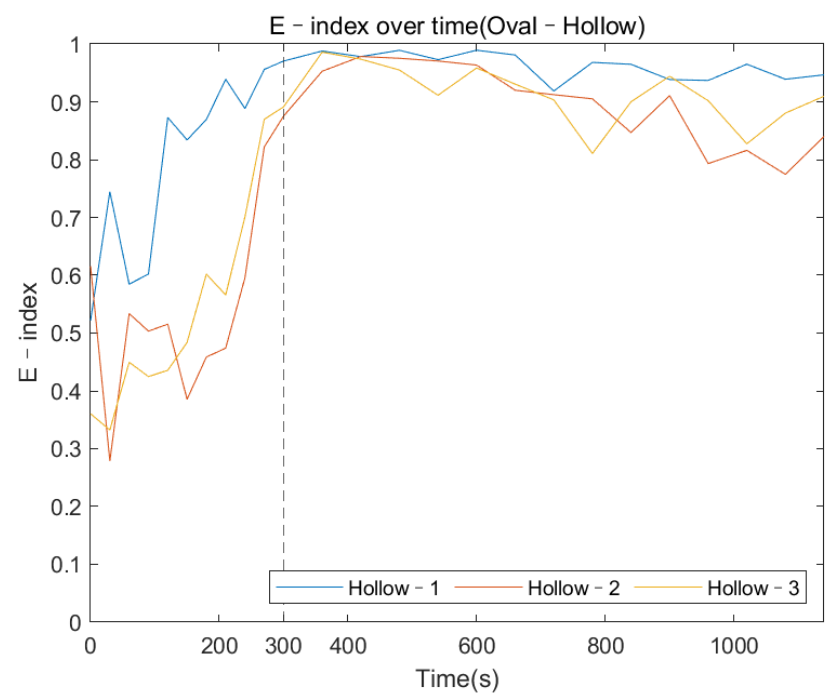

(b)

Figure 15. Variation of E-index at selected frequencies as the cure time increased for the oval implants under (a) solid and (b) hollow conditions.

\section{Discussion}

The variation in the magnitude on the colormap revealed that during the early curing of the epoxy, the implant was not fully integrated with the femur; the vibration of the system was hindered by the high dampening effect of the adhesive, leading to a flat cross-spectrum, except for several strong fundamental vibrational modes located below $1000 \mathrm{~Hz}$, which were not affected by the OI. Due to the increase in stiffness at the femur-implant interface provided by the adhesive, several peaks above $2000 \mathrm{~Hz}$ appeared as the curing of the epoxy, leading to an increase in the E-index, shown in Figures 11 and 12. These results indicate that with the additional axis of the time variation, the colormap could be used to visually inspect the change in the magnitude along with the simulated OI process. More importantly, the result from the oval implant indicated the colormap possesses favorable universality for different cross-section geometries of the residual femur. Based on the appearance of the resonance peaks and the clear step change in the magnitude, the colormap is capable of identifying the change in the femur-implant interface condition, thereby indicating the initial stage of OI.

The result of the E-index over time indicated that E-index was sensitive to the interface stiffness change, especially during the early curing process. This finding suggested that the E-index could potentially be used as a quantitative justification to help with the detection of the initial stage of the OI process. Moreover, the E-index comparison between the solid and hollow conditions indicated the difference in the E-index due to the additional stiffness provided by the solid IM stem, illustrating that the E-index was sensitive to the stiffness change. In addition, the result of the oval-shaped implant demonstrated the capability of the E-index in monitoring the OI process without selecting or identifying the most sensitive resonance frequency based on the geometry of the residual femur. However, there were some fluctuations in the E-index over the cure time. The potential cause of this might be due to the adhesive epoxy not being properly mixed or the adhesive layer not being applied uniformly, which consequentially results in uneven curing at different areas of the IM stem. This added variations in the full cure time and adhesive quality. Furthermore, the maximum bond time for this glue is around $16 \mathrm{~h}$, which is much larger than the experiment time of $19 \mathrm{~min}$. This means that the manual excitation may introduce damage to the interface before the connection reaches its full strength, leading to an unstable E-index.

After the experiment, the implant model was removed from the femur to inspect the condition of the adhesive layer between the femur and implant. Upon inspection, there were clear differences in glue fracture markings between Hollow-3 and the other 
specimens after implant removal. The surfaces of those sufficiently bonded had indications of bonding contacts with glue shear marks, whereas, in Hollow-3, there were minimal indications of these marks (refer to Figure 16). Furthermore, there is evidence that the glue seeped into the medullary cavity and, as a result, did not provide adequate bonding due to an insufficient amount of glue. Nevertheless, this represents a real-life scenario of insufficient OI. According to Figure 13, the E-index with sufficient bonding presented a distinct gradient change around $300 \mathrm{~s}$ and was stable above 0.8 . However, Tri-Hollow-3 demonstrated irregular fluctuations and was unable to reach a steady value of the Eindex along the stimulated OI process. Even though the result of Tri-Hollow-3 showed a clear increase in the level of E-index related to the baseline after $300 \mathrm{~s}$, the inadequate bonding caused by less adhesive, as compared to the other conditions, was identified in the E-index with a clear reduction in value from above 0.8 (which was anticipated as sufficient bonding) to 0.41 . In addition, this insufficient interface stiffness was not capable of providing sufficient resistance to the manual excitation, resulting in damage in the connection, which represented a large variation in the E-index, as shown in Figure 13b. These significant differences in the E-index evidenced that the E-index is able to identify insufficient implant stability and that it is also capable of dynamically monitoring the femur-implant connection during the OI process. Nevertheless, future work will validate the robustness of this strategy by simulating common implant and interface failures.

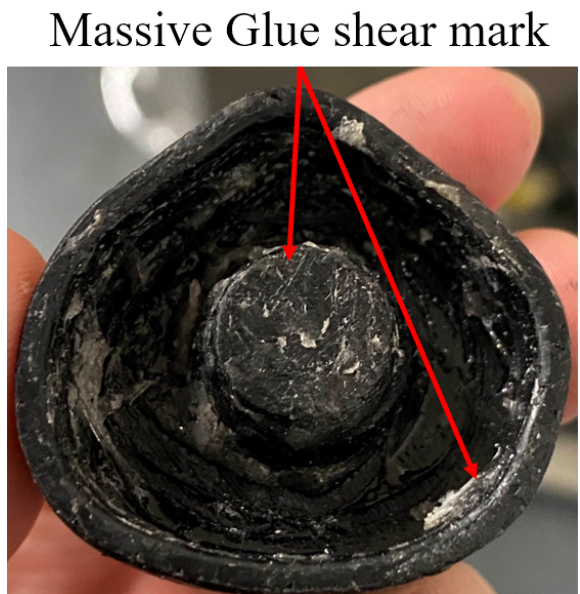

(a)

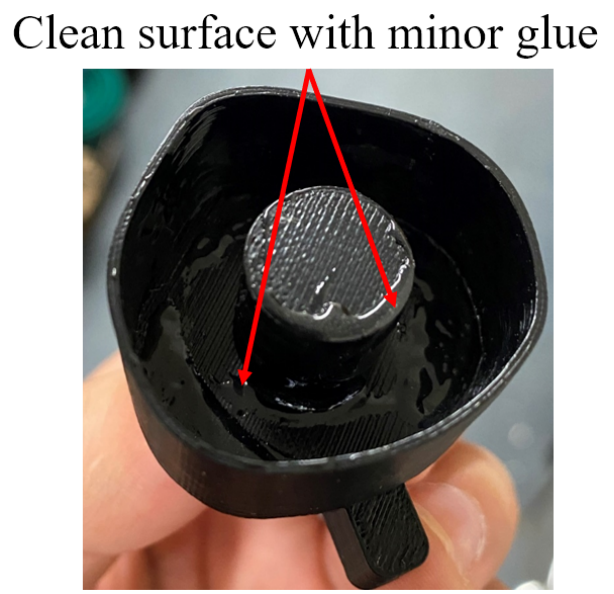

(b)

Figure 16. Implant surface with (a) adequate bonding and (b) insufficient bonding.

Overall, the results displayed a clear trend of the E-index along the stimulated OI process, evidencing the potential of the E-index as a quantitative approach for monitoring the stages of OI. Additionally, the similar trend between the triangular and oval conditions suggests that the E-index is less affected by the geometry of the residual femur's cross-section. Compared to the RFA [2] and modal analysis [20] for the femur-implant system, the E-index quantified the change in the system's energy for a fixed frequency range during the OI process rather than selecting and identifying the specific frequency peaks/modes for a certain implant design or length of the residual femur. In addition, the E-index demonstrated a large increase of $80 \%$ and $50 \%$ for the triangular- and ovalshaped implants, respectively, compared to the 3\% for the RFA [2] and 10-47\% difference and modal analysis [20]. The application of the E-index could be possibly employed as a universal way to assess the OI process for various implant designs and remaining lengths. However, further investigation of the E-index on various lengths of the residual femur and clinical studies are required to develop a robust monitoring technique for the femur-implant system.

The work presented here has outlined the potential of determining implant stability with a sensor located on the external portion of the implant. However, we expect our future work to include an investigation into potential sensing techniques by embedding sensors 
on the extramedullary struts and/or intramedullary stem, which could assess implant stability under in vivo conditions.

\section{Conclusions}

A vibration analysis method has been demonstrated in this paper to assess novel implant stability and monitor the integration of the femur and the implant. The colormap of normalized magnitude against time revealed changes in the resonance peaks at the frequency band of $2000 \mathrm{~Hz}$ to $8000 \mathrm{~Hz}$ as the adhesive cured, identifying the beginning of the stimulated OI process. Moreover, the energy method mentioned in this paper, the E-index, increased by $80 \%$ and $50 \%$ for the triangular- and oval-shaped implants, respectively, along the cure time related to the time of $0 \mathrm{~s}$ during the experiment. These results indicate that the introduction of the E-index quantified the bonding quality between the femur and the implant for continuous monitoring of the OI process. This demonstrates the feasibility of this novel vibrational method for monitoring the OI process. Further work is currently in progress to further investigate the accuracy and reliability of the E-index.

Author Contributions: Conceptualization: S.L., B.S.V. and W.K.C.; methodology, S.L., B.S.V. and W.K.C.; software, S.L.; validation, S.L, B.S.V. and W.K.C.; formal analysis, S.L.; investigation, S.L.; resources, W.K.C.; data curation, S.L.; writing—original draft preparation, S.L.; writing-review and editing, B.S.V., W.K.C., M.R. and M.F.; visualization, S.L.; supervision, W.K.C. and M.R.; project administration, W.K.C., M.R. and M.F.; funding acquisition, W.K.C., M.R. and M.F. All authors have read and agreed to the published version of the manuscript.

Funding: This research is funded by the US Navy Office of Naval Research (N62909-19-1-2051). The financial support provided by the Office of Naval Research is gratefully acknowledged.

Institutional Review Board Statement: Not applicable.

Informed Consent Statement: Not applicable.

Data Availability Statement: The raw / processed data required to reproduce these findings cannot be shared at this time as the data also forms part of an ongoing study.

Acknowledgments: The financial support provided by the Office of Naval Research is gratefully acknowledged.

Conflicts of Interest: The authors declare no conflict of interest.

\section{References}

1. Wang, W.; Lynch, J.P. IWSHM 2017: Application of guided wave methods to quantitatively assess healing in osseointegrated prostheses. Struct. Health Monit. 2018, 17, 1377-1392. [CrossRef]

2. Shao, F.; Xu, W.; Crocombe, A.; Ewins, D. Natural frequency analysis of osseointegration for trans-femoral implant. Ann. Biomed. Eng. 2007, 35, 817-824. [CrossRef] [PubMed]

3. Lee, W.C.; Frossard, L.A.; Hagberg, K.; Haggstrom, E.; Brånemark, R.; Evans, J.H.; Pearcy, M.J. Kinetics of transfemoral amputees with osseointegrated fixation performing common activities of daily living. Clin. Biomech. 2007, 22, 665-673. [CrossRef] [PubMed]

4. Webster, J.B.; Bachus, K.N.; Beck, J.P.; Jeyapalina, S.; Drew, A.J.; Bloebaum, R.D. Osseointegration research. In Full Stride; Springer: Berlin/Heidelberg, Germany, 2017; pp. 167-193.

5. Hebert, J.S.; Rehani, M.; Stiegelmar, R. Osseointegration for lower-limb amputation: A systematic review of clinical outcomes. JBJS Rev. 2017, 5, e10. [CrossRef]

6. Brånemark, R.; Brånemark, P.I.; Rydevik, B.; Myers, R.R. Osseointegration in skeletal reconstruction and rehabilitation: A review. J. Rehabil. Res. Dev. 2001, 38, 175. [PubMed]

7. Hagberg, K.; Brånemark, R. Consequences of non-vascular trans-femoral amputation: A survey of quality of life, prosthetic use and problems. Prosthet. Orthot. Int. 2001, 25, 186-194. [CrossRef] [PubMed]

8. Tomaszewski, P.K. Osseointegrated System for Fixation of Upper Leg Prostheses; Rijksuniversiteit: Groningen, The Netherlands, 2012.

9. Thesleff, A.; Håkansson, B.; Ortiz-Catalan, M. Biomechanical Characterisation of Bone-anchored Implant Systems for Amputation Limb Prostheses: A Systematic Review. Ann. Biomed. Eng. 2018, 46, 377-391. [CrossRef]

10. Tomaszewski, P.; Verdonschot, N.; Bulstra, S.; Verkerke, G.J. A comparative finite-element analysis of bone failure and load transfer of osseointegrated prostheses fixations. Ann. Biomed. Eng. 2010, 38, 2418-2427. [CrossRef]

11. Isaacson, B.M.; Jeyapalina, S. Osseointegration: A review of the fundamentals for assuring cementless skeletal fixation. Orthop. Res. Rev. 2014, 6, 55-65. [CrossRef] 
12. Agarwal, R.; García, A.J. Biomaterial strategies for engineering implants for enhanced osseointegration and bone repair. Adv. Drug Deliv. Rev. 2015, 94, 53-62. [CrossRef]

13. Lu, S.; Vien, B.; Russ, M.; Fitzgerald, M.; Chiu, W. Non-radiative healing assessment techniques for fractured long bones and osseointegrated implant. Biomed. Eng. Lett. 2020, 10, 63-81. [CrossRef] [PubMed]

14. Ward, D.; Robinson, K. Osseointegration for the skeletal fixation of limb prostheses in amputations at the trans-femoral level. The Osseointegration Book: From Calvarium to Calcaneus; Quintessence: Berlin, Germany, 2005; pp. 463-476.

15. Hagberg, K.; Häggström, E.; Jönsson, S.; Rydevik, B.; Brånemark, R. Osseoperception and osseointegrated prosthetic limbs. In Psychoprosthetics; Springer: Berlin/Heidelberg, Germany, 2008; pp. 131-140.

16. Al Muderis, M.; Lu, W.; Tetsworth, K.; Bosley, B.; Li, J.J. Single-stage osseointegrated reconstruction and rehabilitation of lower limb amputees: The Osseointegration Group of Australia Accelerated Protocol-2 (OGAAP-2) for a prospective cohort study. BMJ Open 2017, 7, e013508. [CrossRef] [PubMed]

17. Isaacson, B.M.; Vance, R.E.; Chou, T.G.R.; Bloebaum, R.D.; Bachus, K.N.; Webster, J.B. Effectiveness of resonance frequency in predicting orthopedic implant strength and stability in an in vitro osseointegration model. Resonance 2009, 37, 43-60. [CrossRef] [PubMed]

18. Petersen, R.C. Titanium implant osseointegration problems with alternate solutions using epoxy/carbon-fiber-reinforced composite. Metals 2014, 4, 549-569. [CrossRef] [PubMed]

19. Hickok, N.J.; Shapiro, I.M. Immobilized antibiotics to prevent orthopaedic implant infections. Adv. Drug Deliv. Rev. 2012, 64, 1165-1176. [CrossRef]

20. Cairns, N.J.; Pearcy, M.J.; Smeathers, J.; Adam, C.J. Ability of modal analysis to detect osseointegration of implants in transfemoral amputees: A physical model study. Med. Biol. Eng. Comput. 2013, 51, 39-47. [CrossRef]

21. Cairns, N.J.; Adam, C.J.; Pearcy, M.J.; Smeathers, J. Evaluation of modal analysis techniques using physical models to detect osseointegration of implants in transfemoral amputees. In Proceedings of the Annual International Conference of the IEEE Engineering in Medicine and Biology Society, Boston, MA, USA, 30 August-3 September 2011; pp. 1600-1603.

22. Vayron, R.; Nguyen, V.H.; Lecuelle, B.; Haiat, G. Evaluation of dental implant stability in bone phantoms: Comparison between a quantitative ultrasound technique and resonance frequency analysis. Clin. Implant Dent. Relat. Res. 2018, 20, 470-478. [CrossRef]

23. Chiu, W.K.; Vien, B.S.; Russ, M.; Fitzgerald, M. Healing assessment of fractured femur treated with an intramedullary nail. Struct. Health Monit. 2019, 20, 1475921718816781. [CrossRef]

24. Vien, B.S.; Chiu, W.; Russ, M.; Fitzgerald, M. A Quantitative Approach for the Bone-implant Osseointegration Assessment Based on Ultrasonic Elastic Guided Waves. Sensors 2019, 19, 454. [CrossRef]

25. Alshuhri, A.A.; Holsgrove, T.P.; Miles, A.W.; Cunningham, J.L. Development of a non-invasive diagnostic technique for acetabular component loosening in total hip replacements. Med. Eng. Phys. 2015, 37, 739-745. [CrossRef]

26. Huang, H.-M.; Chiu, C.-L.; Yeh, C.-Y.; Lee, S.-Y. Factors influencing the resonance frequency of dental implants. J. Oral Maxillofac. Surg. 2003, 61, 1184-1188. [CrossRef]

27. Varini, E.; Bialoblocka-Juszczyk, E.; Lannocca, M.; Cappello, A.; Cristofolini, L. Assessment of implant stability of cementless hip prostheses through the frequency response function of the stem-bone system. Sens. Actuators A Phys. 2010, 163, 526-532. [CrossRef]

28. Li, P.; Jones, N.; Gregg, P. Vibration analysis in the detection of total hip prosthetic loosening. Med. Eng. Phys. 1996, 18, 596-600. [CrossRef]

29. Jaecques, S.V.; Pastrav, C.; Van der Perre, G. Analysis of the Fixation Quality of Total Hip Replacements Using a Vibrational Technique. In Proceedings of the ASME 7th Biennial Conference on Engineering Systems Design and Analysis, Manchester, UK, 19-22 July 2004; American Society of Mechanical Engineers: New York, NY, USA, 2004; pp. 579-588.

30. Qi, G.; Paul Mouchon, W.; Tan, T.E. How much can a vibrational diagnostic tool reveal in total hip arthroplasty loosening? Clin Biomech. 2003, 18, 444-458. [CrossRef]

31. Lannocca, M.; Varini, E.; Cappello, A.; Cristofolini, L.; Bialoblocka, E. Intra-operative evaluation of cementless hip implant stability: A prototype device based on vibration analysis. Med. Eng. Phys. 2007, 29, 886-894. [CrossRef]

32. Lu, S.; Vien, B.; Russ, M.; Fitzgerald, M.; Kong, W. Quantitative Monitoring of Osseointegrated Implant Stability Using Vibration Analysis. Mater. Res. Proc. 2021, 18, 87.

33. Xu, D.; Crocombe, A.; Xu, W. Numerical evaluation of bone remodelling associated with trans-femoral osseointegration implant-A 68 month follow-up study. J. Biomech. 2016, 49, 488-492. [CrossRef]

34. Rizzo, P. A review on the latest advancements in the non-invasive evaluation/monitoring of dental and trans-femoral implants. Biomed. Eng. Lett. 2020, 10, 83-102. [CrossRef]

35. Huang, H.M.; Chiu, C.L.; Yeh, C.Y.; Lin, C.T.; Lin, L.H.; Lee, S.Y. Early detection of implant healing process using resonance frequency analysis. Clin. Oral Implant. Res. 2003, 14, 437-443. [CrossRef]

36. Feng, S.-W.; Ho, K.-N.; Chan, Y.-H.; Chang, K.-J.; Lai, W.-Y.; Huang, H.-M. Damping factor as a diagnostic parameter for assessment of osseointegration during the dental implant healing process: An experimental study in rabbits. Ann. Biomed. Eng. 2016, 44, 3668-3678. [CrossRef]

37. Atieh, M.A.; Alsabeeha, N.H.; Payne, A.G.; de Silva, R.K.; Schwass, D.S.; Duncan, W.J. The prognostic accuracy of resonance frequency analysis in predicting failure risk of immediately restored implants. Clin. Oral Implant. Res. 2014, 25, 29-35. [CrossRef] [PubMed] 
38. Michael Norton, B. Primary stability versus viable constraint-A need to redefine. Int. J. Oral Maxillofac. Implant. 2013, $28,19-21$.

39. Mistry, G.; Shetty, O.; Shetty, S.; Singh, R.D. Measuring implant stability: A review of different methods. J. Dent. Implant. 2014, 4, 165. [CrossRef]

40. Manresa, C.; Bosch, M.; Echeverría, J.J. The comparison between implant stability quotient and bone-implant contact revisited: An experiment in B eagle dog. Clin. Oral Implant. Res. 2014, 25, 1213-1221. [CrossRef]

41. Russ, M.; Chiu, W.K.; Ong, W.H.; Tran, T.; Russ, M.; Fitzgerald, M. Development of a Novel Osseointegrated Endoprosthesis, Combing Orthopaedic and Engineering Design Principles, and Structural Health Monitoring Conc. Struct. Health Monit. 2017 2017, 87-94. [CrossRef]

42. Chiu, W.K.; Vien, B.S.; Russ, M.; Fitzgerald, M. Vibration-based healing assessment of an internally fixated femur. J. Nondestruct. Eval. Diagn. Progn. Eng. Syst. 2019, 2, 021003. [CrossRef]

43. Wade, R.; Moorcroft, C.; Thomas, P. Fracture stiffness as a guide to the management of tibial fractures. Bone Jt. J. 2001, 83, 533-535. [CrossRef]

44. Claes, E.L.; Cunningham, L.J. Monitoring the Mechanical Properties of Healing Bone. Clin. Orthop. Relat. Res. 2009, 467, 1964-1971. [CrossRef]

45. Eriksson, C.; Ohlson, K.; Richter, K.; Billerdahl, N.; Johansson, M.; Nygren, H. Callus formation and remodeling at titanium implants. J. Biomed. Mater. Res. Part A Off. J. Soc. Biomater. Jpn. Soc. Biomater. Aust. Soc. Biomater. Korean Soc. Biomater. 2007, 83, 1062-1069. [CrossRef]

46. Chiu, W.K.; Vien, B.S.; Russ, M.; Fitzgerald, M. Healing assessment of an internally fixated femur using vibration analysis. In Proceedings of the 7th Asia-Pacific Workshop on Structural Health Monitoring, Hong Kong, China, 12-15 November 2018; Volume 19, p. 857.

47. Chiu, W.K.; Vien, B.S.; Russ, M.; Fitzgerald, M. Towards a Non-Invasive Technique for Healing Assessment of Internally Fixated Femur. Sensors 2019, 19, 857. [CrossRef]

48. Ong, W.; Chiu, W.; Russ, M.; Chiu, Z. Extending structural health monitoring concepts for bone healing assessment. Fatigue Fract. Eng. Mater. Struct. 2016, 39, 491-501. [CrossRef]

49. Ong, W.; Chiu, W.; Russ, M.; Chiu, Z. Integrating sensing elements on external fixators for healing assessment of fractured femur. Struct. Control. Health Monit. 2016, 23, 1388-1404. [CrossRef]

50. Vien, B.S.; Chiu, W.K.; Russ, M.; Fitzgerald, M. A stress wave-based health monitoring concept on a novel osseointegrated endoprosthesis design. In Proceedings of the 7th Asia-Pacific Workshop on Structural Health Monitoring (APWSHM), Hong Kong, China, 12-15 November 2018. 